\title{
A probable genetic origin for pit defects on the molars of Paranthropus robustus
}

\author{
Ian Towle ${ }^{1}$ and Joel D. Irish ${ }^{1}$ \\ ${ }^{1}$ Research Centre in Evolutionary Anthropology and Palaeoecology, School of Natural \\ Sciences and Psychology, John Moores University, Liverpool, United Kingdom, L3 3AF
}

Number of figures: 2

Number of Tables: 6

Abbreviated title: Paranthropus robustus enamel hypoplasia

Declarations of interest: none

\section{Contact details:}

Ian Towle

Email: ianetowle@hotmail.co.uk

Address: James Parsons Building, Byrom Street, Liverpool, L3 3AF 


\section{Abstract}

We report the frequencies of linear enamel hypoplasia (LEH) and, specifically, pitting enamel hypoplasia (PEH) defects in the teeth of Paranthropus robustus, for comparison with four other South African hominin species and three extant nonhuman primate species. Unlike LEH, the lesser known PEH is characterized by multiple circular depression defects across a tooth crown and is often difficult to interpret in terms of developmental timing and etiology. Teeth in all samples were examined macroscopically with type, position and number of defects recorded. Frequencies of teeth with LEH vary among hominin species, but the differences in PEH are considerable. That is, $P$. robustus has much higher rates of pitting defects, with $47 \%$ of deciduous teeth and $14 \%$ of permanent teeth affected, relative to $6.7 \%$ and $4.3 \%$, respectively, for all other hominin teeth combined; none of the extant primate samples evidence comparable rates. The defects on $P$. robustus molars are unlike those in other species, with entire crowns often covered in small circular depressions. The PEH is most consistent with modern human examples of amelogenesis imperfecta. Additionally, the defects are: 1) not found on anterior teeth, 2) uniform in shape and size, and 3) similar in appearance/severity on all molars. A possible reason for this form of PEH is as a side effect of selection on another phenotype that shares the same coding gene(s), i.e., a genetic origin. Recent research on the ENAM gene provides one such possibility. Paranthropus likely underwent rapid evolution in the ENAM loci, with changes in this gene contributing to larger posterior teeth and thicker enamel. This same gene is associated with amelogenesis imperfecta; therefore, pleiotropy effects, relating to high selection on this gene during Paranthropus evolution, could have yielded this unique condition.

Key words: enamel hypoplasia, primary teeth, dental defects, amelogenesis imperfecta 


\section{Introduction}

Enamel hypoplasia occurs during the secretory stage of formation, whereas other enamel defects form during the maturation stage, e.g., hypocalcification and dental fluorosis (Ten Cate, 1994; Guatelli-Steinberg, 2015; Xing et al., 2015). Defects take a variety of forms, most of which have been found in fossil hominins (e.g., Tobias, 1967; Goodman et al., 1987; Moggi-Cecchi, 2000; Lukacs et al., 2001; Guatelli-Steinberg et al., 2004; Xing et al., 2015). A range of disturbances can create similar defects, often making a diagnosis of particular etiologies difficult. Nonetheless, enamel hypoplasia may be able to provide some insight into diet, genetic conditions, environment factors and health of individuals and populations (e.g., Cunha, 2004; Ogden et al., 2007; Schuurs, 2012; Guatelli-Steinberg et al., 2014).

Enamel hypoplasia is often split into three broad categories: linear (LEH), pit (PEH) and plane-form (Pindborg, 1970; Seow, 1990). Defects can look remarkably different, but ultimately all are associated with a reduction of enamel matrix from disruption in ameloblast production (Eversole, 1984). It is not always easy to assign defects to these categories (e.g., Ogden, 2007), but doing so is often justified because they can have specific etiologies. In particular, genetic conditions, injuries to the tooth during formation, and certain diseases can cause characteristic hypoplasia defects (Cook, 1980; Goodman \& Rose, 1991; Skinner \& Newell, 2003; Weerheijm, 2003; Crawford et al., 2007; Ogden et al., 2008).

Methods for recording enamel hypoplasia vary among studies. Most researchers record and compare LEH frequencies (e.g., Guatelli-Steinberg, 2004; Miszkiewicz, 2015; Smith et al., 2016). Others include all defects (e.g., Goodman et al., 1980, 1984; Goodman \& Armelagos, 1985; Ogilvie et al., 1989). Some studies only record defects on certain teeth, with posterior and deciduous teeth excluded (e.g., Infante \& Gillespie, 1974; Lovell \& Whyte, 1999). Additionally, it 
is not always clear if the pitting hypoplasia mentioned only refers to defects found as part of LEH bands (e.g., Mellanby, 1929; Sognnaes, 1956; Goodman et al., 1980, 1984; Goodman \& Armelagos, 1985; Hillson, 1992).

Pitting enamel hypoplasia may take a variety of forms, ranging from small circular pinpricks to vast irregular depressions (Skinner, 1996; Hillson \& Bond, 1997; Witzel et al., 2006; Ogden, 2007). Pits also vary in distribution across a tooth crown, with some forming rows around the circumference, usually associated with shallow defects, and others more randomly scattered (Goodman \& Rose, 1990). PEH can also be associated with plane-form hypoplasia (e.g., Ogden et al., 2007; Lauc et al., 2015), though commonly it is the only defect observed.

The location of PEH does not necessarily give insight into the age of the individual when the defect formed. The reason is that pit depth is related to its position on the plane of the brown striae of Retzius on which enamel matrix formation ceased. Deep pits may, therefore, represent a disturbance much earlier than their crown position suggests. A further issue in studying PEH is that it is not yet clear why it forms instead of other hypoplasia types, particularly LEH. However, the tooth involved, position on the crown, and cause of the disruption are all important factors. Typically, only the occlusal type of perikymata is affected. Molars have significantly more of their crown surface covered with this type, which may explain why they often have more PEH (Hillson \& Bond, 1997; Hillson, 2014). However, it has also been suggested that because it is uncommon for an individual to have both LEH and PEH, these different hypoplasia types may have different etiologies (Lovell \& Whyte, 1999).

Each pit corresponds to the ceasing of ameloblast activity at a particular point in enamel formation. However, it is not clear why only certain ameloblasts are affected along the plane of a brown stria of Retzius during formation (Witzel et al., 2006; Ogden et al., 2007). In some cases, only a few ameloblasts stop forming enamel matrix, leading to small pits. With large pits, 
hundreds of these enamel-forming cells may cease production (Guatelli-Steinberg, 2015). In other forms of systemic enamel hypoplasia, such as LEH and plane form, all ameloblast activity is affected. In most instances of PEH the enamel between pits appears normal. Exposed Tomes' process pits can often be observed within pits, showing a sharp end to the ameloblasts; however, some examples show continued deposition of irregular enamel (Hillson \& Bond, 1997; Witzel et al., 2006).

In most cases of PEH described in the literature, particularly in archaeological examples, researchers have not been able to specify a cause; instead, some form of non-specific stress was suggested. Nevertheless, PEH has been associated with a number of specific disturbances in modern clinical studies, including: hypocalcaemia, premature birth, low birth weight, hypoparathyroidism, neonatal tetany, maternal diabetes mellitus, kernicterus, vitamin D deficiency, congenital syphilis, amelogenesis imperfecta, and nutritional deficiency (Eliot et al., 1934; Grahnen \& Selander, 1954; Croft et al., 1965; Purvis et al., 1973; Stimmler et al., 1973; Pisanty et al., 1977; Nikiforuk \& Fraser, 1979, 1981; Seow et al., 1984; Wright et al., 1993; Aine et al., 2000; Pinhasi et al., 2006; Gaul et al., 2015; Radu \& Soficaru, 2016).

Differences in PEH frequencies among fossil hominins and extant primates have rarely been explored. Pitting enamel hypoplasia has, however, been found on the teeth of various hominin specimens (e.g., Tobias, 1967; Ogilvie et al., 1989; Xing et al., 2015; Zanolli et al., 2016). Some studies have noted the presence of PEH in P. robustus teeth (Robinson, 1956; White, 1978; Moggi-Cecchi, 2000; Moggi-Cecchi et al., 2010). These South African hominin studies have been in the context of hypoplasia rates as a whole, and to date a cause for these defects has not been explored. In the present study, PEH frequencies and appearance in P. robustus will be compared with those in other hominins and extant primates; a differential diagnosis to explain these unusual defects will follow. 


\section{Materials and Methods}

Of 431 P. robustus teeth, 127 (29.47\%) could not be recorded for hypoplasia due to crown damage or post-mortem discoloration, leaving 304 teeth for the study. The comparative material includes specimens assigned to Early Homo, Australopithecus sediba, Homo naledi, A. africanus, gorillas, chimpanzees and baboons (Table 1). The South African fossil hominin samples are curated at the University of the Witwatersrand and The Ditsong National Museum of Natural History. The extant primate samples are curated at the Powell-Cotton Museum. All of the latter individuals were killed in their natural habitat and comprise western lowland gorillas (Gorilla gorilla gorilla), common chimpanzees (Pan troglodytes) and olive baboons (Papio anubis) (Dean \& Jones, 1992; GuatelliSteinberg \& Skinner, 2000; Lukacs, 2001).

Table 1. Number of observable teeth for each species.

\begin{tabular}{lccc} 
Species & Teeth observable & Not observable & \% Unobservable \\
\hline Early Homo & 47 & 19 & 28.79 \\
A. sediba & 10 & 1 & 9.09 \\
P. robustus & 304 & 127 & 29.47 \\
H. naledi & 142 & 14 & 8.97 \\
A. africanus & 360 & 122 & 25.31 \\
Gorilla gorilla gorilla & 1693 & 392 & 18.80 \\
Pan troglodytes & 1837 & 677 & 26.93 \\
Papio anubis & 774 & 92 & 10.62 \\
\hline
\end{tabular}

Teeth were observed macroscopically, with a 10x hand lens used to clarify defect types. The presence and position of linear, localized, pitting and plane-form hypoplasia were recorded for each tooth, along with defect size and shape. All teeth were viewed under an incandescent 
lamp and slowly rotated so light hit at a variety of angles to discern even the smallest of defects. The presence of PEH was recorded, and notes on position described. If pits were part of an LEH defect, the position of the LEH was recorded and pitting noted; however, this form of pitting is not included in the PEH analysis. To compare certain defect types, as well as between species, a chi-square test of homogeneity with significance set at the 0.05 alpha level was used.

In some cases, micro-CT scans of $P$. robustus molars were viewed and defect size and number recorded. In particular, CT scans of six teeth with defined defects were viewed to take precise measurements of pit diameter and get a better understanding of defect depth and uniformity. The most defined pits that show up on the CT scanned 3D model were recorded after corroboration with photos of the specimen. Between 15 and 20 defects were measured for each tooth, with mean and range recorded. The scans were completed by the Department of Human Evolution, Max Planck Institute for Evolutionary Anthropology with a BIR ACTIS 225/300 (kV, 100 mA, 0.25 brass filter) or a SkyScan 1172 (100 kV, $94 \mathrm{~mA}, 2.0 \mathrm{~mm}$ aluminium and copper filter) microtomographic scanner. The isometric voxel sizes resulting from these scans range between 15 and 50 micrometres (mm) (Skinner, personal communication, 2018).

Data are presented by tooth count, where the number of hypoplastic teeth is displayed as a percentage of the total number of observable teeth. Because the hominin material is fragmentary, this approach yields maximum sample size for comparison; additionally, Lovell and Whyte (1999) note that displaying on a 'per-tooth' rather than 'per-individual' basis also permits a broader comparison of subsamples of different tooth groups among populations. Antimeres are treated as separate data points in the overall hypoplasia frequencies. This strategy increases sample sizes and allows maximum recovery of information. Two additional points justify including antimeres: 1) some defects may be displayed on one side and not the other, in particular, localized 
defects, and 2) the nature of the fossil record means that, in some cases, correctly assigning antimeres is difficult.

Instead of rejecting teeth worn past a certain point, all crowns that are unbroken due to post-mortem damage were included. This approach allows inclusion of teeth that may have had enamel defects worn away during life. However, excluding worn teeth also leads to bias, since an entire sample would consist of individuals who died young, i.e., potentially more ill, on average, during dental development than those who lived to old age. Additionally, many defects remain visible even when the tooth has significant wear, particularly PEH defects in P. robustus.

\section{Results}

The $P$. robustus sample exhibits an extremely high rate of $\mathrm{PEH}$, far higher than any extant primate or fossil hominin sample studied (Tables 2 and 3). There is a statistically significant difference in PEH in permanent teeth between $P$. robustus and the other hominins and primates (e.g., $P$. robustus vs. $A$. africanus $\left.\mathrm{X}^{2}=14.823,1 \mathrm{df}, \mathrm{p}=0.0001\right)$. The case is similar for deciduous teeth $(P$. robustus vs. $A$. africanus $\left.\mathrm{X}^{2}=5.824,1 \mathrm{df}, \mathrm{p}=0.0158\right)$.

The first, second and third permanent molars of $P$. robustus are similarly affected, with over $20 \%$ displaying PEH defects. Therefore, the high PEH rates on permanent teeth of $P$. robustus are related predominately to molars, although premolars also exhibit high rates relative to the other hominin species (Table 4). For the permanent dentition as a whole, $P$. robustus has more teeth with PEH than LEH. 
Table 2. Per tooth frequencies (\%) of Pitting Enamel Hypoplasia (PEH), Linear Enamel Hypoplasia (LEH), and localized hypoplasia for permanent teeth of each species.

\begin{tabular}{lccc}
\multicolumn{1}{c}{ Species } & PEH (\# teeth) & LEH (\# teeth) & Localized (\# teeth) \\
\hline Pan troglodytes & $0.65(12 / 1837)$ & $8.06(148 / 1837)$ & $0.98(18 / 1837)$ \\
Gorilla gorilla gorilla & $2.89(49 / 1693)$ & $4.25(72 / 1693)$ & $0.95(16 / 1693)$ \\
Papio anubis & $0.00(0 / 774)$ & $2.07(16 / 774)$ & $1.68(13 / 774)$ \\
H. naledi & $0.70(1 / 142)$ & $14.79(21 / 142)$ & $0.70(1 / 142)$ \\
A. africanus & $5.03(18 / 358)$ & $15.08(54 / 358)$ & $0.28(1 / 358)$ \\
P. robustus & $14.75(41 / 278)$ & $11.51(32 / 278)$ & $1.08(3 / 278)$ \\
Early Homo & $0.00(0 / 47)$ & $8.51(4 / 47)$ & $2.13(1 / 47)$ \\
A. sediba & $0.00(0 / 10)$ & $0.00(0 / 10)$ & $0.00(0 / 10)$ \\
& & & \\
\hline
\end{tabular}

Table 3. Per tooth frequencies (\%) of Pitting Enamel Hypoplasia (PEH) and localized hypoplasia for deciduous teeth of each species.

\begin{tabular}{lcc} 
Species & PEH (\# teeth) & Localized (\# teeth) \\
\hline Pan troglodytes & $4.23(25 / 591)$ & $5.08(30 / 591)$ \\
Gorilla gorilla gorilla & $1.39(6 / 433)$ & $12.93(56 / 433)$ \\
Papio anubis & $0.00(0 / 107)$ & $3.74(4 / 107)$ \\
H. naledi & $0.00(0 / 16)$ & $0.00(0 / 16)$ \\
A. africanus & $5.00(2 / 19)$ & $0.00(0 / 19)$ \\
P. robustus & $41.30(19 / 46)$ & $0.00(0 / 46)$ \\
Early Homo & $14.29(2 / 14)$ & $0.00(0 / 14)$ \\
\hline
\end{tabular}


Table 4. Per tooth frequencies (\%) for Pitting Enamel Hypoplasia (PEH) and Linear Enamel Hypoplasia (LEH) in the three largest hominin samples, for different tooth groups of permanent teeth.

\begin{tabular}{|c|c|c|c|c|c|c|}
\hline \multirow[t]{2}{*}{ Permanent teeth } & \multicolumn{2}{|c|}{ P. robustus } & \multicolumn{2}{|c|}{ A. africanus } & \multicolumn{2}{|c|}{ H. naledi } \\
\hline & $\underline{\mathrm{PEH}}$ & $\underline{\text { LEH }}$ & $\underline{\mathrm{PEH}}$ & $\underline{\text { LEH }}$ & $\underline{\mathrm{PEH}}$ & $\underline{\text { LEH }}$ \\
\hline Anterior teeth & $1.75(1 / 57)$ & $22.81(13 / 57)$ & $2.11(2 / 95)$ & $40.00(38 / 95)$ & $2.04(1 / 49)$ & $24.49(12 / 49)$ \\
\hline Premolars & $7.04(5 / 71)$ & $9.86(7 / 71)$ & $0.00(0 / 90)$ & $6.67(6 / 90)$ & $0.00(0 / 39)$ & $23.08(9 / 39)$ \\
\hline First molars & $21.43(12 / 56)$ & $5.36(3 / 56)$ & $6.90(4 / 58)$ & $5.17(3 / 58)$ & $0.00(0 / 25)$ & $0.00(0 / 25)$ \\
\hline Second molars & $21.57(11 / 51)$ & $5.88(3 / 51)$ & $9.09(6 / 66)$ & $6.06(4 / 66)$ & $0.00(0 / 19)$ & $0.00(0 / 19)$ \\
\hline Third molars & $25.58(11 / 43)$ & $11.63(5 / 43)$ & $10.20(5 / 49)$ & $4.08(2 / 49)$ & $0.00(0 / 10)$ & $0.00(0 / 10)$ \\
\hline
\end{tabular}

In the deciduous teeth of $P$. robustus, PEH defects also occur primarily on molars (Table 5). The first and second deciduous molars, in both jaws, are similarly affected, with PEH present on $54 \%$ and $52 \%$ of these teeth, respectively; indeed, the crown is often completely covered, to resemble dimples on a golf ball (Figure 1). On both permanent and deciduous teeth of $P$. robustus, severe PEH often covers large areas of the crown, and characteristically comprises numerous uniform small depressions. Pits are typically more defined toward the occlusal surface. Defects vary little in size or shape, and hundreds of separate pits are often visible across the crown, with nearly identical defects evident in both permanent and deciduous molars (Figure 2; Table 6).

Table 5. Percentage of deciduous P. robustus teeth with Pitting Enamel Hypoplasia (PEH).

\begin{tabular}{lccc} 
Deciduous Teeth & PEH \% & Total teeth & Teeth with hypoplasia \\
\hline All teeth & 41.30 & 46 & 19 \\
Anterior teeth & 8.33 & 12 & 1 \\
First molars & 53.85 & 13 & 7 \\
Second molars & 52.38 & 21 & 11 \\
\hline
\end{tabular}


In deciduous molar antimeres with $\mathrm{PEH}$, both tend to have mirror-image defects. For example, the right and left second deciduous molars of SK 61 not only have a similar distribution of uniform pits, but areas where the most defined defects are present is identical. These pits were clearly not made post-mortem, and the surrounding enamel does not seem to have been reduced, i.e., it appears to be of normal density (Figure 2). The rate of PEH is similar between P. robustus sites. At Kromdraii $16.67 \%$ of permanent teeth have PEH, while at Swartkrans this figure is $14.34 \%$. Anterior teeth associated with affected permanent molars do not show an increase in LEH defects, as only $16.67 \%$ of these teeth are affected.
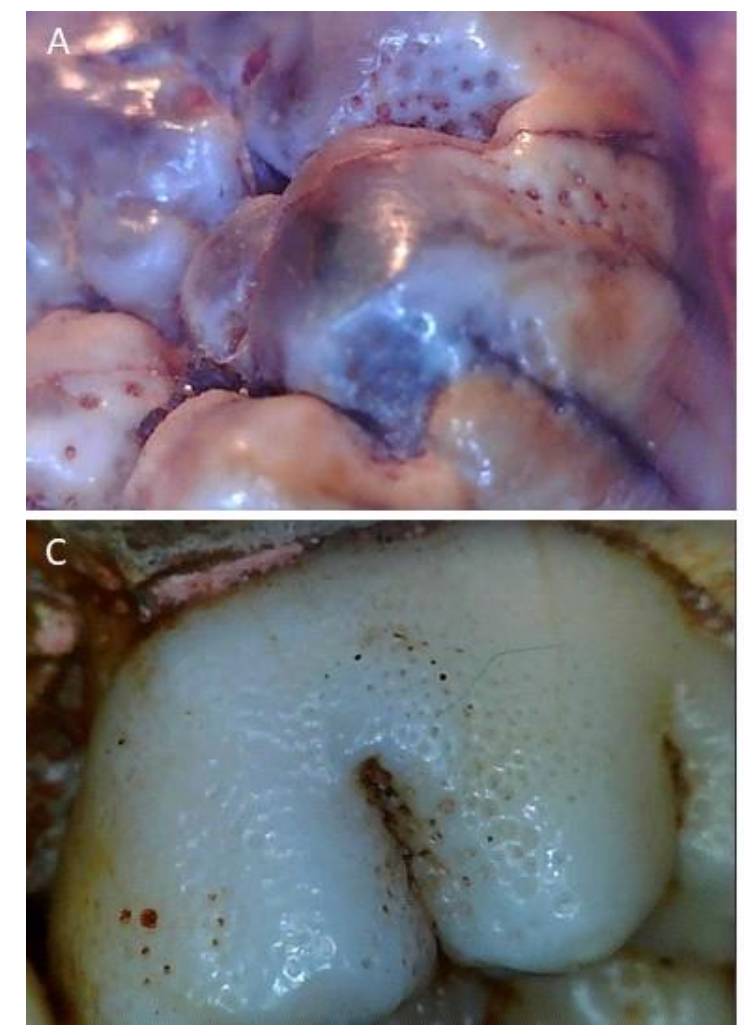
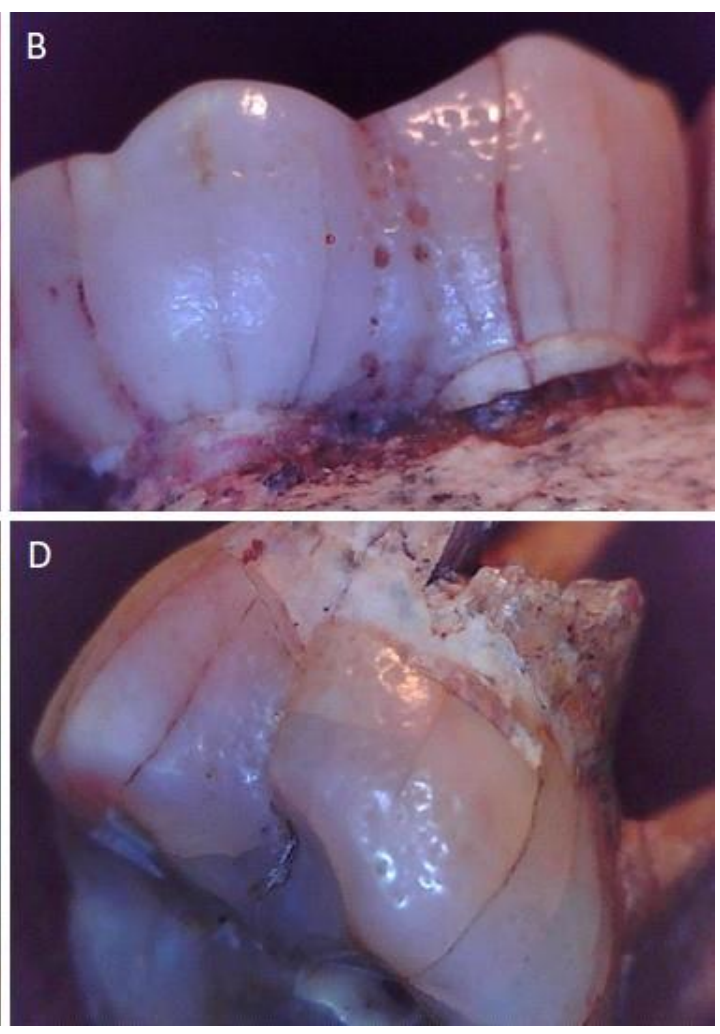

Figure 1. Uniform circular pitting enamel hypoplasia on four P. robustus teeth. A) SK 61; B) SK 63; C) SK 64; D) SK 90. 
Table 6. Number and size of $P$. robustus pitting defects. Pit size is in millimeters. L: left; R: right; $\mathrm{d}$ : deciduous; M1: first molar; M2: second molar. A total of 15-20 of the most defined pits was analyzed for each specimen. All mandibular teeth except SK 89.

\begin{tabular}{ccccc} 
Specimen & Number of pits & Minimum pit size & Maximum pit size & Average \\
\hline SK 61: RM1 & $50+$ & 0.12 & 0.36 & 0.23 \\
SK 61: RdM2 & $80+$ & 0.11 & 0.28 & 0.17 \\
SK 61: LdM2 & $80+$ & 0.12 & 0.26 & 0.18 \\
SK 63: RdM2 & $100+$ & 0.11 & 0.42 & 0.23 \\
SK 64: RdM2 & $300+$ & 0.12 & 0.21 & 0.16 \\
SK 89: LM1 & $100+$ & 0.12 & 0.26 & 0.16 \\
\hline
\end{tabular}
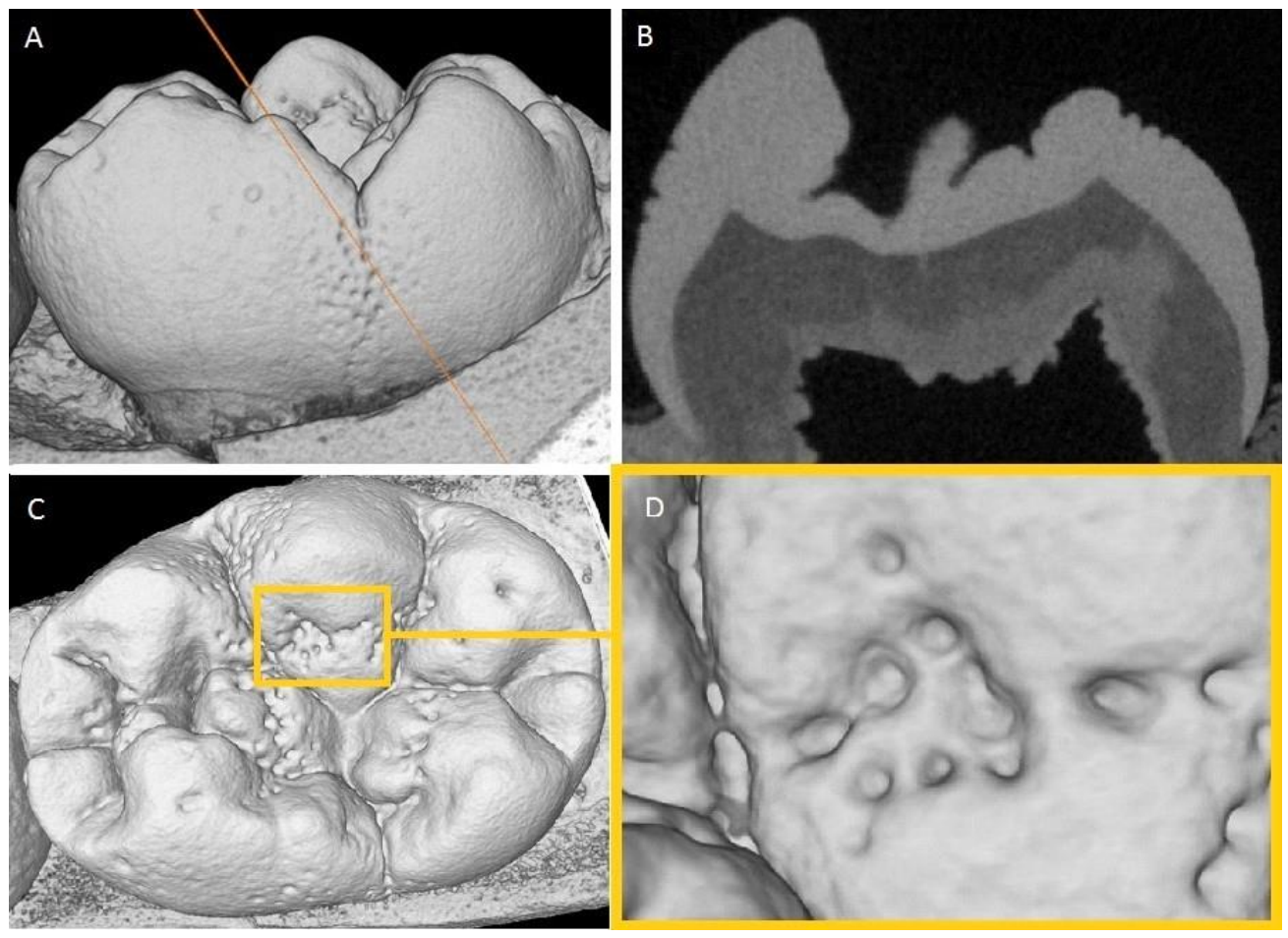

Figure 2. Micro-CT scan slices of SK 64 (P. robustus), right mandibular first molar. A) Overview of the lingual surface with the orange line the position of the slice in B; B) Slice showing pitting on both the lingual and buccal surfaces. C) Occlusal view; D) Close up of pitting on the occlusal surface. 


\section{Discussion}

Few studies have reported on different types of hypoplasia, and, in particular, it is uncommon to report PEH frequencies. Lovell and Whyte (1999) studied a human sample from Ancient Mendes, Egypt, finding that linear defects were over three times more common than pitting defects. However, their permanent teeth samples only consisted of anterior teeth. Similarly, Goodman et al. (1987) compared frequencies of pitting between deciduous and permanent anterior teeth, finding higher frequencies in the latter. In a modern sample, Pedersen (1944) found $14 \%$ of two to four-year-old children had enamel hypoplasia in their teeth. Typically, in human samples, the frequency of hypoplasia in deciduous teeth is $\leq 5 \%$ (e.g., Lovell \& Whyte, 1999; Robles et al., 2013). However, studies focusing on humans severely affected by disease, famine, or malnutrition show much higher rates, with $18 \%$ to $62 \%$ of teeth affected (Enwonwu, 1973; Infante \& Gillespie, 1974; Seow, 1990). Ogilvie et al. (1989) found a high rate in Neanderthals. Half of those defects on the posterior teeth were of the PEH variety. Deciduous teeth also showed pitting, but at a rate of just 3.9\%. The authors note that later developing Neanderthal teeth seem more affected, with an increasing number of defects from the first to third molars. This low frequency in deciduous teeth and permanent first molars stands in stark contrast to that of $P$. robustus, with deciduous molars most affected.

Due to the lack of known frequencies in other samples, it is not known how common PEH is in hominins overall. That said, it is clear from the present results, as well as in studies of modern humans, that the PEH rate in P. robustus is remarkably high (Goodman et al., 1987; Ogilvie et al., 1989; Seow et al., 1992). Such defects are also evident on $P$. robustus posterior teeth not included in this study, from Drimolen and Cooper's, as well as similar PEH in P. boisei (Tobias, 1967; de Ruiter et al., 2009; Moggi-Cecchi et al., 2010). The frequency of these defects across sites suggests 
P. robustus, and perhaps the greater Paranthropus genus, shared this tendency for 'golf ball-like' enamel defects.

Extant ape species studied to date do not have high PEH rates, and the appearance of defects varies from those in $P$. robustus. Additionally, the PEH on P. robustus molars does not resemble hypoplastic defects in many modern clinical studies of deciduous teeth, including those caused by premature birth, low birth weight, vitamin D deficiency, tuberous sclerosis, congenital syphilis, pseudohypoparathyrgidism and epidermolysis bullosa (Croft et al., 1965; Purvis et al., 1973; Stimmler et al., 1973; Nikiforuk \& Fraser, 1979, 1981; Seow et al., 1984; Wright et al., 1993; Aine et al., 2000; Pinhasi et al., 2006; Gaul et al., 2015; Radu \& Soficaru, 2016). Most of these conditions are associated with pitting that is irregular in both shape and distribution. They also tend to affect all teeth, not just molars, and are associated with other types of dental defects.

Pitting defects have also been associated with deficiencies or surpluses of certain compounds. For example, dental fluorosis can create pit like features on tooth crowns (Fejerskov et al., 1990); they can manifest in several ways but mostly as white opaque lines that, in extreme cases, can lend a chalky white appearance to the entire crown (Fejerskov et al., 1990; Xing et al., 2015). If the fluorosis is severe, the outer enamel may eventually fracture to leave cracks or pitsthough the latter have edges that appear jagged or broken under magnification (Thylstrup \& Fejerskov, 1978). Another effect of dental fluorosis, particularly in severe cases, is discoloration. The $P$. robustus teeth do not show any of these features, so fluorosis is unlikely. Other compounds, e.g., mercury, can create enamel defects during dental development (Ogden, 2007; loannou et al., 2015; Radu \& Soficaru, 2016). Similarly, a common cause of prenatal enamel hypoplasia has been linked to calcium deficiency in the mother, from malnutrition or malabsorption (Lovell \& Whyte, 1999). Postnatal defects have also been linked to hypocalcaemia, from insufficient calcium consumption or malabsorption. The defects in P. robustus do appear consistent with such an 
etiology, so perhaps they result from a specific environmental or dietary component, or absence thereof. That said, the lack of affected anterior teeth is not supportive of this scenario.

Ogden et al. (2007) describe a human sample with high hypoplasia rates in deciduous and permanent dentitions from 16th-18th Century London. Superficially, some defects look similar to the pitting on P. robustus molars. Yet, the pitting is less uniform, with evidence of both planeform and pitted defects. Additionally, the cusp morphology in the London sample is affected in many teeth, which does not appear to be the case for $P$. robustus. The example in Hillson (2014) of PEH in a modern deciduous first molar and plane form defects on the second deciduous molar and canine, is suggested as a case of 'neonatal dental hypoplasia', in which a stress at birth is the cause. Thus, a potential hypothesis is that the $P$. robustus defects form at or around birth, perhaps from an environmental or nutritional disturbance. However, two issues counter this hypothesis: 1) the lack of associated hypoplasia on other deciduous teeth, and 2) pitting is equally present on all permanent molars.

A neonatal line can be found in a variety of populations, affecting those teeth forming at birth; in humans, this means the deciduous dentition and first permanent molars. It is thought to result from either a decrease in plasma calcium after birth (Norén et al., 1984; Smith \& Avishai, 2005) or disturbances from the birth process (Whittaker \& Richards, 1978; Guatelli-Steinberg, 2015). Although not explored in many fossil hominin samples, if neonatal lines are found in the deciduous and permanent first molars of $P$. robustus with pitting, inferences into timing may be permitted. Unfortunately, at present, the only $P$. robustus tooth for which these data are available is not pitted (Smith et al., 2015). If the defects are not genetic in origin, and at least some PEH defects are formed in utero, then it likely relates to nutritional factors in the mother (Seow, 1990; Lukacs, 1992; Lovell \& Whyte, 1999). Clearly, however, PEH defects on second and third permanent molars indicate a postnatal etiology. 
Perhaps the thick enamel and faster development of Paranthropus molars compared to other hominin species (Lacruz et al., 2008) meant that they were more predisposed to developmental defects. For example, the shape of the crown and the structure of the enamel may have meant that even a slight disturbance during development resulted in severe defects. A single brown stria of Retzius affected by pockets of ameloblasts ceasing enamel matrix formation could potentially yield surprisingly large areas of PEH (Hillson and Bond, 1997; Witzel et al., 2006). Therefore, PEH in P. robustus, in which the entire crown is covered in small uniform depressions, could potentially have been caused by a relatively brief disturbance. Brich \& Dean (2013) found that in modern humans: 1 ) second deciduous molars form enamel at a slower rate than other deciduous teeth, and 2) the cusps of deciduous second molars have thicker enamel and take proportionally longer to form. Disturbances occurring whilst molar cusps are still forming can lead to pitting defects over large areas of the crown (Hillson, 2014). Therefore, it is a possibility that PEH defects on $P$. robustus deciduous molars may relate to the thick enamel and developmental timing of these teeth. This possibility would explain why defects are much less common on the anterior teeth. However, a disturbance event is still necessary to cause the defects, so the uniform appearance and common occurrence makes this hypothesis unlikely.

The pitting in P. robustus resemble certain modern cases of amelogenesis imperfecta. This set of genetic disorders affects one in every 700 to 14,000 modern humans (Sundell \& Koch, 1984; Crawford et al., 2007). Defects usually include scattered pits and plane form hypoplasia but abnormal colouration, thickness and density of the enamel is also common (Wright, 1985; Aldred et al., 2003; Chamarthi et al., 2012; Schuurs, 2012; Towle et al., 2017). A specific type called hypoplastic amelogenesis imperfecta (Wright, 1993; Mehta et al., 2013) most closely emulates the defects in P. robustus, in that it commonly does not show coloration, thickness and density abnormalities of the enamel (Witkop \& Sauk, 1976; Witkop, 1988; Seow, 1992). Indeed, the pitting 
defects look very similar to some examples of this type of amelogenesis imperfecta (e.g., Figure 3 of Rushton, 1964; Ozdemir et al., 2005). A recent study highlighted a particular genetic mutation that causes defects to be present on posterior, but not anterior primary teeth (Kim et al., 2016). Therefore, it may be possible that the PEH on P. robustus molars is genetic in origin. The fact that both deciduous and permanent molars are similarly affected and that all defects are essentially identical in appearance supports this possibility.

Of course, it would be important to understand the reason(s) for such a high rate of 'genetically-related' enamel defects in P. robustus from an evolutionary perspective. Enamel hypoplasia predisposes teeth to caries and extreme wear. Yet, specimens assigned to $P$. robustus with PEH from different sites, along with potentially similar pitting in east African Paranthropus specimens, suggest this type of defect was common for an extended period of time.

Recent advances in genetic analyses of dental development may suggest a likely scenario. Rapid evolution of a particular feature can lead to loss of genomic stability in particular genes, or create pleiotropy effects on other characteristics (Pavlicev \& Cheverud, 2015; Fiddes et al., 2018; Hlusko et al., 2018). For example, Hlusko et al. (2018) found the EDAR gene to be under intense selection in certain populations during the last ice age, relating to transmission of vitamin $D$ and fatty acids; the same populations show specific dental characteristics associated with changes in this gene. Perhaps the Paranthropus PEH defects are also a genetic by-product, caused by changes in gene(s) associated with other dental properties.

Genomic research has begun to explore genetic loci involved in enamel formation, mostly with the aim of understanding development, but also for inferences into genetic conditions (Paine et al., 2001; Hu \& Yamakoshi, 2003; Hu et al., 2005; Ozdemir et al., 2005; Al-Hashimi et al., 2009). One such gene, ENAM, has been analyzed for differences among primate species (Kelley \& 
Swanson, 2008). Evidence of adaptive ENAM evolution was implicated in observed interspecific variation in enamel thickness. Areas of this gene show signs of strong positive selection, probably related to enamel thickness changes (Horvath et al., 2014). Mutations in this same gene are responsible for many types of amelogenesis imperfecta (Crawford et al., 2007; Kelley \& Swanson, 2008; Wang et al., 2015). Therefore, it is plausible that the genetic changes related to the evolution of extremely thick enamel and large posterior teeth in Paranthropus, over a relatively short period, created pleiotropy effects, including high rates of $\mathrm{PEH}$.

In sum, comparisons of the frequencies and appearance of enamel hypoplasia defects among several fossil hominin and extant primate samples suggest that several potential causes for severe PEH on P. robustus molars can be ruled out. Given that: 1 ) substantially less defects are present on the species' anterior teeth, 2) defects are relatively uniform in shape and size, and 3) all molars are similarly affected, the hypothesis that best fits the data is a genetic origin for 'golf ball'-like PEH. A plausible scenario is that specific genetic mutations resulted in these defects and concerns the evolution of thick enamel and/or large posterior teeth in Paranthropus.

\section{Acknowledgements}

The authors thank L. Berger and B. Zipfel from the University of the Witwatersrand, I. Livne from the Powell-Cotton Museum, and S. Potze from the Ditsong Museum of South Africa for access to their collections. For producing the CT scans provided by Ditsong Museum of South Africa we thank J.J. Hublin and the Department of Human Evolution, Max Planck Institute for Evolutionary Anthropology. For technical assistance we thank M. Skinner. This research was supported by a studentship to the first author from Liverpool John Moores University. 


\section{References}

Aine, L., Backström, M. C., Mäki, R., Kuusela, A. L., Koivisto, A. M., Ikonen, R. S., \& Mäki, M., 2000. Enamel defects in primary and permanent teeth of children born prematurely. Journal of Oral Pathology \& Medicine 29, 403-409.

Aldred, M. J., Savarirayan, R., \& Crawford, P. J. M., 2003. Amelogenesis imperfecta: a classification and catalogue for the 21st century. Oral Diseases 9, 19-23.

Al-Hashimi, N., Sire, J. Y., \& Delgado, S., 2009. Evolutionary analysis of mammalian enamelin, the largest enamel protein, supports a crucial role for the 32-kDa peptide and reveals selective adaptation in rodents and primates. Journal of Molecular Evolution 69, 635.

Brich, W. and Dean, M.C., 2013. A new method of calculating human deciduous enamel formation times. Bulletin of the International association for paleodontology 7, 47-55.

Chamarthi, V., Varma, B. R., \& Jayanthi, M., 2012. Amelogenesis imperfecta: A clinician's challenge. Journal of Indian Society of Pedodontics and Preventive Dentistry 30, 70.

Collins Cook, D., 1980. Hereditary enamel hypoplasia in a prehistoric Indian child. Journal of Dental Research 59, 1522-1522.

Crawford, P. J., Aldred, M., \& Bloch-Zupan, A., 2007. Amelogenesis imperfecta. Orphanet Journal of Rare Diseases 2, 17-29. 
Croft, L. K., Witkop, C. J., \& Glas, J. E., 1965. Pseudohypoparathyroidism. Oral Surgery, Oral Medicine, Oral Pathology 20, 758-770.

Cunha, E., Rozzi, F. R., Bermúdez de Castro, J. M., Martinón-Torres, M., Wasterlain, S. N., \& Sarmiento, S., 2004. Enamel hypoplasias and physiological stress in the Sima de los Huesos Middle Pleistocene hominins. American Journal of Physical Anthropology 125, 220-231.

de Ruiter, D. J., Pickering, R., Steininger, C. M., Kramers, J. D., Hancox, P. J., Churchill, S. E., ... \& Backwell, L., 2009. New Australopithecus robustus fossils and associated U-Pb dates from Cooper's cave (Gauteng, South Africa). Journal of Human Evolution 56, 497-513.

Dean, M. C., Jones, M. E., \& Pilley, J. R., 1992. The natural history of tooth wear, continuous eruption and periodontal disease in wild shot great apes. Journal of Human Evolution 22, 23-39.

Eliot, M. M., Souther, S. P., Anderson, B. G., \& Arnim, S. S., 1934. A study of the teeth of a group of school children previously examined for rickets. American Journal of Diseases of Children 48, 713-729.

Enwonwu, C. O., 1973. Influence of socio-economic conditions on dental development in Nigerian children. Archives of Oral Biology 18, 95-IN15.

Eversole, L. R., 1984. Clinical outline of oral pathology: diagnosis and treatment. Lea \& Febiger publishers, Philadelphia. 
Fejerskov, O., Manji, F., \& Baelum, V., 1990. The nature and mechanisms of dental fluorosis in man. Journal of Dental Research 69, 692-700.

Fiddes, I.T., Lodewijk, G.A., Mooring, M., Bosworth, C.M., Ewing, A.D., Mantalas, G.L., Novak, A.M., van den Bout, A., Bishara, A., Rosenkrantz, J.L. and Lorig-Roach, R., 2018. Human-specific NOTCH2NL genes affect Notch signaling and cortical neurogenesis. Cell 173, 1356-1369.

Gaul, J. S., Grossschmidt, K., Gusenbauer, C., \& Kanz, F., 2015. A probable case of congenital syphilis from pre-Columbian Austria. Anthropologischer Anzeiger 72, 451-472.

Goodman, A. H., \& Armelagos, G. J., 1985. The chronological distribution of enamel hypoplasia in human permanent incisor and canine teeth. Archives of Oral Biology 30, 503-507.

Goodman, A. H., \& Rose, J. C., 1990. Assessment of systemic physiological perturbations from dental enamel hypoplasias and associated histological structures. American Journal of Physical Anthropology 33(S11), 59-110.

Goodman, A. H., \& Rose, J. C., 1991. Dental enamel hypoplasias as indicators of nutritional status. In: Kelley, M. A., \& Larsen, C. S. (Eds.), Advances in dental anthropology. Wiley-Liss, New York, pp. 279-293.

Goodman, A. H., Allen, L. H., Hernandez, G. P., Amador, A., Arriola, L. V., Chavez, A., \& Pelto, G. H., 1987. Prevalence and age at development of enamel hypoplasias in Mexican children. American Journal of Physical Anthropology 72, 7-19. 
Goodman, A. H., Armelagos, G. J., \& Rose, J. C., 1980. Enamel hypoplasias as indicators of stress in three prehistoric populations from Illinois. Human Biology 515-528.

Goodman, A. H., Armelagos, G. J., \& Rose, J. C., 1984. The chronological distribution of enamel hypoplasias from prehistoric Dickson Mounds populations. American Journal of Physical Anthropology 65, 259-266.

Grahnen, H., \& Selander, P., 1954. The effect of rickets and spasmophilia on the permanent dentition. Odontologisk Revy 5, 7.

Guatelli-Steinberg, D., 2015. Dental stress indicators from micro- to macroscopic. In: Irish, J. D., \& Scott, G. R. (Eds.), A companion to dental anthropology. Wiley-Blackwell, Hoboken, pp. 450464.

Guatelli-Steinberg, D., \& Skinner, M., 2000. Prevalence and etiology of linear enamel hypoplasia in monkeys and apes from Asia and Africa. Folia Primatologica 71, 115-132.

Guatelli-Steinberg, D., Larsen, C. S., \& Hutchinson, D. L., 2004. Prevalence and the duration of linear enamel hypoplasia: a comparative study of Neandertals and Inuit foragers. Journal of Human Evolution 47, 65-84.

Guatelli-Steinberg, D., Stinespring-Harris, A., Reid, D. J., Larsen, C. S., Hutchinson, D. L., \& Smith, T. M., 2014. Chronology of linear enamel hypoplasia formation in the Krapina Neanderthals. PaleoAnthropology 431, 431-445. 
Hillson, S., 2014. Tooth development in human evolution and bioarchaeology. Cambridge University Press, Cambridge.

Hillson, S. W., 1992. Dental enamel growth, perikymata and hypoplasia in ancient tooth crowns. Journal of the Royal Society of Medicine 85, 460-466.

Hillson, S., \& Bond, S., 1997. Relationship of enamel hypoplasia to the pattern of tooth crown growth: a discussion. American Journal of Physical Anthropology 104, 89-103.

Hlusko, L.J., Carlson, J.P., Chaplin, G., Elias, S.A., Hoffecker, J.F., Huffman, M., Jablonski, N.G., Monson, T.A., O'Rourke, D.H., Pilloud, M.A. and Scott, G.R., 2018. Environmental selection during the last ice age on the mother-to-infant transmission of vitamin $D$ and fatty acids through breast milk. Proceedings of the National Academy of Sciences 173, 1356-1369.

Horvath, J. E., Ramachandran, G. L., Fedrigo, O., Nielsen, W. J., Babbitt, C. C., Clair, E. M. S., ... \& Wall, C. E., 2014. Genetic comparisons yield insight into the evolution of enamel thickness during human evolution. Journal of Human Evolution 73, 75-87.

Hu, J. C. C., Yamakoshi, Y., Yamakoshi, F., Krebsbach, P. H., \& Simmer, J. P., 2005. Proteomics and genetics of dental enamel. Cells Tissues Organs 181(3-4), 219-231.

Hu, J. C., \& Yamakoshi, Y., 2003. Enamelin and autosomal-dominant amelogenesis imperfecta. Critical Reviews in Oral Biology \& Medicine 14, 387-398. 
Hu, J. C., \& Yamakoshi, Y., 2003. Enamelin and autosomal-dominant amelogenesis imperfecta.

Critical Reviews in Oral Biology \& Medicine 14, 387-398.

Hu, J. C., Yamakoshi, Y., Yamakoshi, F., Krebsbach, P. H., \& Simmer, J. P., 2006. Proteomics and genetics of dental enamel. Cells Tissues Organs 181, 219-231.

Infante, P. F., \& Gillespie, G. M., 1974. An epidemiologic study of linear enamel hypoplasia of deciduous anterior teeth in Guatemalan children. Archives of Oral Biology 19, 1055-1061.

loannou, S., Henneberg, M., Henneberg, R. J., \& Anson, T., 2015. Diagnosis of mercurial teeth in a possible case of congenital syphilis and tuberculosis in a 19th century child skeleton. Journal of Anthropology 2015, 1-11.

Kelley, J. L., \& Swanson, W. J., 2008. Dietary change and adaptive evolution of enamelin in humans and among primates. Genetics 178, 1595-1603.

Kim, Y. J., Shin, T. J., Hyun, H. K., Lee, S. H., Lee, Z. H., \& Kim, J. W., 2016. A novel de novo mutation in LAMB3 causes localized hypoplastic enamel in the molar region. European Journal of Oral Sciences 124, 403-405.

Lacruz, R.S., Dean, M.C., Ramirez-Rozzi, F. and Bromage, T.G., 2008. Megadontia, striae periodicity and patterns of enamel secretion in Plio-Pleistocene fossil hominins. Journal of Anatomy 213, 148-158. 
Lauc, T., Fornai, C., Premužić, Z., Vodanović, M., Weber, G. W., Mašić, B., \& Šikanjić, P. R., 2015.

Dental stigmata and enamel thickness in a probable case of congenital syphilis from XVI century Croatia. Archives of Oral Biology 60, 1554-1564.

Lovell, N. C., \& Whyte, I., 1999. Patterns of dental enamel defects at ancient Mendes, Egypt. American Journal of Physical Anthropology 110, 69-80.

Lukacs, J. R., 1992. Dental paleopathology and agricultural intensification in South Asia: new evidence from Bronze Age Harappa. American Journal of Physical Anthropology 87, 133-150.

Lukacs, J. R., 2001. Enamel hypoplasia in the deciduous teeth of great apes: variation in prevalence and timing of defects. American Journal of Physical Anthropology 116, 199-208.

Mehta, D. N., Shah, J., \& Thakkar, B., 2013. Amelogenesis imperfecta: Four case reports. Journal of Natural Science, Biology, and Medicine 4, 462-465.

Mellanby, M., 1929. Diet and the teeth: an experimental study. Part I. Dental structure in dogs. Medical Research Council, London.

Miszkiewicz, J. J., 2015. Linear Enamel Hypoplasia and Age-at-Death at Medieval (11th-16th Centuries) St. Gregory's Priory and Cemetery, Canterbury, UK. International Journal of Osteoarchaeology 25, 79-87. 
Moggi-Cecchi, J., 2000. Enamel hypoplasia in South African early hominids: A reappraisal.

American Journal of Physical Anthropology 30, 230-231.

Moggi-Cecchi, J., Menter, C., Boccone, S., \& Keyser, A., 2010. Early hominin dental remains from the Plio-Pleistocene site of Drimolen, South Africa. Journal of Human Evolution 58, 374-405.

Nikiforuk, G., \& Fraser, D., 1979. Etiology of enamel hypoplasia and interglobular dentin: the roles of hypocalcemia and hypophosphatemia. Metabolic Bone Disease and Related Research 2, 17-23.

Nikiforuk, G., \& Fraser, D., 1981. The etiology of enamel hypoplasia: a unifying concept. The Journal of Pediatrics 98, 888-893.

Norén, J. G., Odelius, H., Rosander, B., \& Linde, A., 1984. SIMS analysis of deciduous enamel from normal full-term infants, low birth weight infants and from infants with congenital hypothyroidism. Caries Research 18, 242-249.

Ogden, A., 2008. Advances in the palaeopathology of teeth and jaws. In: Pinhasi, R., \& Mays, S. (Eds.), Advances in Human Palaeopathology. John Wiley \& Sons, Hoboken, pp. 283-307.

Ogden, A. R., Pinhasi, R., \& White, W. J., 2007. Gross enamel hypoplasia in molars from subadults in a 16th-18th century London graveyard. American Journal of Physical Anthropology 133, 957-966. 
Ogilvie, M. D., Curran, B. K., \& Trinkaus, E., 1989. Incidence and patterning of dental enamel hypoplasia among the Neandertals. American Journal of Physical Anthropology 79, 25-41.

Ozdemir, D., Hart, P. S., Firatli, E., Aren, G., Ryu, O. H., \& Hart, T. C., 2005. Phenotype of ENAM mutations is dosage-dependent. Journal of dental research 84, 1036-1041.

Paine, M. L., White, S. N., Luo, W., Fong, H., Sarikaya, M., \& Snead, M. L., 2001. Regulated gene expression dictates enamel structure and tooth function. Matrix Biology 20, 273-292.

Pavličev, M. and Cheverud, J.M., 2015. Constraints evolve: context dependency of gene effects allows evolution of pleiotropy. Annual Review of Ecology, Evolution, and Systematics 46, 413434.

Pedersen, P. O., 1944. Taendernes tilstand hos 2-6 aarige børn. Tandlaegebladet 48, 485-565.

Pindborg, J. J., 1970. Pathology of the dental hard tissues. W. B. Saunders Company, Philadelphia.

Pinhasi, R., Shaw, P., White, B., \& Ogden, A. R., 2006. Morbidity, rickets and long-bone growth in post-medieval Britain-a cross-population analysis. Annals of Human Biology 33, 372-389.

Pisanty, S., \& Garfunkel, A., 1977. Familial hypoparathyroidism with candidiasis and mental retardation. Oral Surgery, Oral Medicine, Oral Pathology 44, 374-383. 
Purvis, R. J., MacKay, G. S., Cockburn, F., Barrie, W. M., Wilkinson, E. M., Belton, N. R., \& Forfar, J. O., 1973. Enamel hypoplasia of the teeth associated with neonatal tetany: a manifestation of maternal vitamin-D deficiency. The Lancet 302, 811-814.

Radu, C., \& Soficaru, A. D., 2016. Dental developmental defects in a subadult from 16th-19th centuries Bucharest, Romania. International Journal of Paleopathology 15, 33-38.

Robinson, J. T., 1956. The dentition of the Australopithecinae: Maxillary molars. Transvaal Museum Memoirs 9, 81-100.

Robles, M., Ruiz, M., Bravo Pérez, M., González, E., \& Peñalver, M., 2013. Prevalence of enamel defects in primary and permanent teeth in a group of schoolchildren from Granada (Spain). Oral Medicine and Pathology 18, 187-193.

Rushton, M. A., 1964. Hereditary enamel defects. Proceedings of the Royal Society of Medicine 57, 53-58.

Rutherford, B., Spångberg, L., Tucker, M., \& Charette, M., 1995. Transdentinal stimulation of reparative dentine formation by osteogenic protein-1 in monkeys. Archives of Oral Biology 40, 681-683.

Schuurs, A., 2012. Pathology of the hard dental tissues. John Wiley \& Sons, Hoboken. 
Seow, W. K., 1990. Enamel hypoplasia in the primary dentition: a review. Journal of Dentistry for Children 58, 441-452.

Seow, W. K., 1992. Clinical diagnosis and management strategies of amelogenesis imperfecta variants. Pediatric Dentistry 15, 384-393.

Seow, W. K., Brown, J. P., Tudehope, D. A., \& O'Callaghan, M., 1984. Dental defects in the deciduous dentition of premature infants with low birth weight and neonatal rickets. Pediatric Dentistry 6, 88-92.

Skinner, M., 1996. Developmental stress in immature hominines from Late Pleistocene Eurasia: evidence from enamel hypoplasia. Journal of Archaeological Science 23, 833-852.

Skinner, M. F., \& Newell, E. A., 2003. Localized hypoplasia of the primary canine in bonobos, orangutans, and gibbons. American Journal of Physical Anthropology 120, 61-72.

Smith, C. E., Murillo, G., Brookes, S. J., Poulter, J. A., Silva, S., Kirkham, J., ... \& Mighell, A. J., 2016. Deletion of amelotin exons 3-6 is associated with amelogenesis imperfecta. Human Molecular Genetics 25, 3578-3587.

Smith, P., \& Avishai, G., 2005. The use of dental criteria for estimating postnatal survival in skeletal remains of infants. Journal of Archaeological Science 32, 83-89.

Smith, T. M., Tafforeau, P., Le Cabec, A., Bonnin, A., Houssaye, A., Pouech, J., ... \& Menter, C. G., 2015. Dental ontogeny in Pliocene and early Pleistocene hominins. PloS one 10, e0118118. 
Sognnaes, R. F., 1956. Histologic evidence of developmental lesions in teeth originating from

Paleolithic, prehistoric, and ancient man. The American Journal of Pathology 32, 547-577.

Stimmler, L., Snodgrass, G. J. A. I., \& Jaffe, E., 1973. Dental defects associated with neonatal symptomatic hypocalcaemia. Archives of Disease in Childhood 48, 217-220.

Sundell, S., \& Koch, G., 1984. Hereditary amelogenesis imperfecta. I. Epidemiology and clinical classification in a Swedish child population. Swedish Dental Journal 9, 157-169.

Ten Cate, A. R., \& Nanci, A., 1994. Structure of the oral tissues. In: Ten Cate, A. R. (Ed.), Oral Histology: Development, Structure, Function. Mosby Year Book, St. Louis, pp. 45-57.

Thylstrup, A., \& Fejerskov, O., 1978. Clinical appearance of dental fluorosis in permanent teeth in relation to histologic changes. Community Dentistry and Oral Epidemiology 6, 315-328.

Tobias, P. V., 1967. Olduvai Gorge (Vol. 2). Cambridge University Press, Cambridge.

Towle, I., Irish, J.D. and De Groote, I., 2018. Amelogenesis imperfecta in the dentition of a wild chimpanzee. Journal of medical primatology 47, 117-119.

Wang, X., Zhao, Y., Yang, Y., \& Qin, M., 2015. Novel ENAM and LAMB3 mutations in Chinese families with hypoplastic amelogenesis imperfecta. PloS One 10, e0116514. 
Weerheijm, K. L., 2003. Molar incisor hypomineralisation (MIH). European Journal of Paediatric Dentistry 4, 115-120.

White, T. D., 1978. Early hominid enamel hypoplasia. American Journal of Physical Anthropology 49, 79-83.

Whittaker, D. K., \& Richards, D., 1978. Scanning electron microscopy of the neonatal line in human enamel. Archives of Oral Biology 23, 45-50.

Witkop, C. J., 1988. Amelogenesis imperfecta, dentinogenesis imperfecta and dentin dysplasia revisited: problems in classification. Journal of Oral Pathology \& Medicine 17, 547-553.

Witkop Jr, C. J., \& Sauk Jr, J.J., 1976. Heritable defects of enamel. In: Prescott, G., \& Stewart, R. (Eds), Oral facial genetics. CV Mosby Company, St Louis, pp. 151-226.

Witzel, C., Kierdorf, U., Dobney, K., Ervynck, A., Vanpoucke, S. and Kierdorf, H., 2006. Reconstructing impairment of secretory ameloblast function in porcine teeth by analysis of morphological alterations in dental enamel. Journal of anatomy 209, 93-110.

Wright, J. T., 1985. Analysis of a kindred with amelogenesis imperfecta. Journal of Oral Pathology \& Medicine 14, 366-374.

Wright, J. T., Fine, J. D., \& Johnson, L., 1993. Hereditary epidermolysis bullosa: oral manifestations and dental management. Pediatric Dentistry 15, 242-242. 
bioRxiv preprint doi: https://doi.org/10.1101/400671; this version posted August 27, 2018. The copyright holder for this preprint (which was not certified by peer review) is the author/funder, who has granted bioRxiv a license to display the preprint in perpetuity. It is made available under aCC-BY-NC-ND 4.0 International license.

Xing, S., Guatelli-Steinberg, D., O'Hara, M., Li, J., Wei, P., Liu, W., \& Wu, X., 2015. Micro-CT

imaging and analysis of enamel defects on the early late pleistocene xujiayao

juvenile. International Journal of Osteoarchaeology 26, 935-946.

Zanolli, C., Dean, M. C., Assefa, Y., Bayle, P., Braga, J., Condemi, S., ... \& Macchiarelli, R., 2016.

Structural organization and tooth development in a Homo erectus juvenile mandible from the

Early Pleistocene site of Garba IV at Melka Kunture, Ethiopian highlands. American Journal of

Physical Anthropology 162, 533-549. 